\title{
FAKTOR-FAKTOR YANG MEMPENGARUHI KEIKUTSERTAAN PROGRAM PIL KB PADA PUS DI WILAYAH KERJA PUSKESMAS MABELOPURA PALU
}

\author{
${ }^{1}$ Diky Hardiyansyah, ${ }^{*}$ Nita Damayanti \\ ${ }^{1}$ Program Studi Pendidikan Dokter, Fakultas Kedokteran Universitas Alkhairat, Jl. Diponegoro No. 39 \\ Palu 94221, Sulawesi Tengah, Indonesia \\ *Corresponding author: Telp: +62811451689 email: nita.unisa@gmail.com
}

\begin{abstract}
ABSTRAK
Pemilihan metode kontrasepsi merupakan upaya yang dilakukan seorang wanita untuk mencari metode kontrasepsi yang cocok dengan kondisinya, hal ini karena menu pilihan kontrasepsi dipengaruhi oleh ragam metode yang ada. Penelitian ini bertujuan untuk mengetahui faktor-faktor yang mempengaruhi keikutsertaan PUS terhadap program KB. Pengambilan data dilakukan dengan tehnik wawancara, dengan menggunakan desain case control dan dilakukan di wilayah kerja Puskesmas Mabelopura dengan jumlah sampel sebanyak 96 orang. Populasi penelitian adalah PUS peserta KB pil dan suntik di wilayah kerja Pusekesmas Mabelopura yang memenuhi kriteria. Hasil penelitian menunjukkan bahwa pengaruh faktor demografi (umur, agama) mempunyai nilai $\mathrm{P}$ yang tidak bermakna $(\mathrm{P}>$ 0,05), untuk faktor sosio-ekonomi (tingkat pendidikan, pendapatan) mempunyai nilai $\mathrm{P}$ yang tidak bermakna $(\mathrm{P}>0,05)$, faktor jumlah anak mempunyai nilai $\mathrm{P}$ yang tidak bermakna $(\mathrm{P}>$ $0,05)$, faktor riwayat penyakit mempunyai nilai $\mathrm{P}$ yang tidak bermakna, faktor pengaruh orang lain mempunyai nilai P yang tidak bermakna, dan faktor pengaruh media massa (koran, $\mathrm{TV}$, dan radio) juga mempunyai nilai $\mathrm{P}$ yang tidak bermakna $(>0,05)$.
\end{abstract}

Kata Kunci : Kontrasepsi, KB suntik, KB pil

\section{ABSTRACT}

The choice of contraceptive method is an attempt by a woman to find a contraceptive method that suits her condition, this is because the menu of contraceptive choices is influenced by the variety of available methods. This study aims to determine the factors that influence EFA participation in family planning programs. Data was collected by interview technique, using a case control design and conducted in the working area of Mabelopura Public Health Center with a sample size of 96 people. The study population was EFA participants in the pill and injection contraception in the Mabelopura Pusekesmas working area that met the criteria. The results showed that the influence of demographic factors (age, religion) had a $P$ value that was not significant ( $P>0.05$ ), for socio-economic factors (education level, income) had a $P$ value that was not significant $(P>0.05)$, the factor of the number of children has a $P$ value that is not significant $(P>0.05)$, the history of disease has a $P$ value that is not significant, the influence factor of others has a $P$ value that is not significant, and the influence factor of the mass media (newspapers, $T V$, and radio) also has a $P$ value that is not significant (>0.05).

Keywords: Contraception, injection contraception, pills contraception

\section{PENDAHULUAN}

Menurut World Health Organisation (WHO) expert committee 1997, keluarga berencana adalah tindakan yang membantu pasangan suami istri untuk menghindari kehamilan yang tidak diinginkan, mendapatkan kelahiran yang memang sangat diinginkan, mengatur interval diantara kehamilan, mengontrol waktu saat kelahiran dalam hubungan dengan umur suami istri serta menentukan jumlah anak dalam keluarga., Keluarga berencana menurut Undang-Undang No 52 tahun 2009 (tentang perkembangan kependudukan dan pembangunan keluarga sejahtera) adalah upaya mengatur kelahiran anak, jarak, dan usia ideal melahirkan, 
mengatur kehamilan, melalui promosi, perlindungan, dan bantuan sesuai dengan hak reproduksi untuk mewujudkan keluarga yang berkualitas. ${ }^{4}$ Keluarga berencana atau yang disebut family planning/planned parenthood merupakan suatu usaha menjarangkan atau merencanakan jumlah dan jarak kehamilan dengan menggunakan kontrasepsi. ${ }^{5}$ Kontrasepsi ialah usaha-usaha untuk mencegah terjadinya kehamilan. Usaha-usaha itu dapat bersifat sementara, dapat juga bersifat permanen. Yang bersifat permanen dinamakan pada wanita tubektomi dan pada pria vasektomi. ${ }^{8}$

Pemilihan metode kontrasepsi merupakan upaya yang dilakukan seorang wanita untuk mencari metode kontrasepsi yang cocok dengan kondisinya, hal ini karena menu pilihan kontrasepsi dipengaruhi oleh ragam metode yang ada. Ragam metode yang ditawarkan oleh suatu program didasarkan pada banyak faktor, misalnya kebijakan faktor nasional, ketersediaan fasilitas dan petugas kesehatan, biaya, dan lain sebagainya. Kecocokan antara suatu metode kontrasepsi dan setiap klien bergantung pada sejumlah faktor. Dalam memutuskan metode mana yang akan digunakan, seorang wanita dipengaruhi oleh kepentingan pribadi, pertimbangan kesehatan, biaya, aksesibilitas, dan lingkungannya. ${ }^{1,2}$

Ada beberapa alasan seorang wanita atau pasangan mengubah pilihan dari satu metode kontrasepsi ke metode lainnya, misalnya karena efek samping yang tidak dapat ditoleransi, jumlah keluarga yang diinginkan sudah tercapai, metode tidak lagi dianjurkan secara medis, dan lain sebagainya. ${ }^{1}$

Berdasarkan hasil survei yang dilakukan oleh BKKBN tahun 2011 menunjukkan metode KB hormonal yaitu suntikan dan pil merupakan metode yang paling dominan digunakan oleh peserta $\mathrm{KB}$ di enam wilayah Indonesia, dan pada penelitian penggunaan MKJP yang dilakukan enam wilayah Indonesia tersebut didapatkan ada beberapa faktor yang mempengaruhi pasangan dalam pemilihan kontrasepsi. ${ }^{2}$ Hasil tersebut sesuai dengan hasil survei data sekunder yang dilakukan oleh penulis. Data dari Puskesmas Mabelopura yang memiliki 5 wilayah kerja dimana setiap tahunnya mengalami perubahan dari jumlah peserta baru yang ikut program KB khususnya yang menggunakan metode kontrasepsi hormonal yaitu pil KB. Untuk tahun 2008 mengalami peningkatan menjadi 1292 peserta, tetapi tahun 2009 mengalami penurunan yang signifikan yaitu menjadi 260 peserta. Tahun 2010 mengalami peningkatan jumlah peserta menjadi 596 peserta baru yang ikut serta. Namun, pada tahun 2011 kembali mengalami penurunan jumlah peserta pil KB yang ikut serta yaitu menjadi 345 orang. Data tersebut menunjukkan perubahan setiap tahunnya. Sehingga penulis ingin mencari tahu apakah ada faktor-faktor yang mempengaruhi peserta $\mathrm{KB}$ untuk mengikuti program $\mathrm{KB}$ khususnya kontrasepsi Pil.

\section{METODOLOGI}

Desain penelitian yang digunakan adalah penelitian yang bersifat observasional dengan menggunakan case control study. Pelaksanaan penelitian dimulai bulan Mei dan selesai bulan Oktober tahun 2012 di poli KIA (Kesehatan Ibu dan Anak) KB Puskesmas Mabelopura, Kecamatan Palu Selatan, selain itu di laksanakan juga di posyandu, dan rumah warga yang masih berada di wilayah kerja Puskesmas Mabelopura. Populasi penelitian ini adalah PUS peserta KB pil dan suntik di wilayah kerja Pusekesmas Mabelopura yang memenuhi kriteria inklusi. Kriteria Inklusi adalah peserta KB pil yang terdaftar di wilayah kerja Puskesmas Mabelopura, peserta yang tinggal di wilayah kerja Puskesmas Mabelopura, peserta yang berusia 15-45 tahun, peserta yang bersedia ikut penelitian tanpa paksaan. Kriteria eksklusi adalah PUS yang memiliki data registrasi yang tidak lengkap dan PUS yang tuna rungu suami-istri. Sampel pada penelitian ini berjumlah 163 orang, namun yang berhasil diwawancarai adalah 48 orang. Dan tehnik sampling yang digunakan adalah consecutive random sampling.

\section{HASIL DAN PEMBAHASAN HASIL}

Data yang dikumpulkan merupakan karakteristik demografi responden (umur dan agama), karakteristik sosio-ekonomi (tingkat pendidikan dan pendapatan), jumlah anak, riwayat penyakit, pengaruh orang lain, dan pengaruh media massa. Untuk hasil analisis 
statistik ditampilkan dengan sistematika sebagai berikut:

Tabel 1. Karakteristik Demografi (umur dan agama) yang Mempengaruhi Keikutsertaan PUS Terhadap Program Pil KB

\begin{tabular}{lcc}
\hline & Frekuensi & $\begin{array}{c}\text { Persentas } \\
\text { e }(\%)\end{array}$ \\
\hline Umur & 30 & 31.3 \\
15-25 tahun & 53 & 55.2 \\
26-35 tahun & 13 & 13.5 \\
36-45 tahun & 96 & 100.0 \\
\hline \multicolumn{2}{c}{ Total } & \\
\hline Agama & 88 & 91.7 \\
Islam & 2 & 2.1 \\
Kristen Katolik & 4 & 4.2 \\
Kristen & 2 & 2.1 \\
Protestan & 96 & 100.0 \\
Hindu & \multicolumn{1}{c}{ Total } &
\end{tabular}

Sumber: Data primer

Pada tabel 1 menunjukkan bahwa karakteristik umur terhadap keikutsertaan responden pada program KB pil dari 96 responden terbanyak pada pada kelompok usia 26-35 tahun sebanyak 53 orang $(55,2 \%)$. Pada karakteristik agama terhadap keikutsertaan responden pada program KB pil dari 96 responden yaitu terbanyak pada kelompok agama Islam sebanyak 88 orang $(91,7 \%)$.

Tabel 2. Karakteristik Sosio-Ekonomi yang Mempengaruhi Keikutser-taan PUS Terhadap Program Pil KB

\begin{tabular}{lcc}
\hline & Frekuensi & $\begin{array}{c}\text { Persentase } \\
(\%)\end{array}$ \\
\hline Pendapatan & & \\
Rendah & 47 & 49.0 \\
Menengah & 40 & 41.7 \\
Tinggi & 9 & 9.4 \\
\hline \multicolumn{1}{c}{ Total } & 96 & 100.0 \\
\hline Tingkat & & \\
Pendidikan & & \\
\hline Rendah & 18 & 18.8 \\
Menengah & 69 & 71.9 \\
Tinggi & 9 & 9.4 \\
\hline \multicolumn{1}{c}{ Total } & 96 & 100.0 \\
\hline
\end{tabular}

Sumber: Data primer

Tabel 2 menunjukkan bahwa pengaruh pendapatan terhadap keikutsertaan responden pada program KB pil dari 96 responden yaitu pada kelompok pendapatan rendah sebanyak 47 orang $(49,0 \%)$. Untuk pengaruh tingkat pendidikan terhadap keikutsertaan responden pada program KB pil dar 96 responden yaitu terbanyak pada kelompok menengah sebanyak 69 orang $(71,9 \%)$.

Tabel 3. Faktor Jumlah Anak yang Mempengaruhi Keikutsertaan PUS Terhadap Program Pil KB

\begin{tabular}{ccc}
\hline Jumlah Anak & Frekuensi & $\begin{array}{c}\text { Persentase } \\
(\%)\end{array}$ \\
\hline Kurang & 24 & 25.0 \\
Sedang & 39 & 40.6 \\
Banyak & 33 & 34.4 \\
Total & 96 & 100.0 \\
\hline
\end{tabular}

Sumber: Data primer

Tabel 3 menunjukkan bahwa pengaruh jumlah anak terhadap keikutsertaan responden pada program KB pil yaitu pada kelompok yang memiliki jumlah anak kurang sebanyak 24 orang $(25,0 \%)$.

Tabel 4. Riwayat penyakit yang Mempengaruhi Keikutsertaan PUS Terhadap Program Pil KB di Wilayah Kerja Puskesmas Mabelopura

\begin{tabular}{lcc}
\hline & Frekuensi & $\begin{array}{c}\text { Persentasi } \\
(\%)\end{array}$ \\
\hline PJK & 1 & 1.0 \\
Ada & 95 & 99.0 \\
Tidak ada & & \\
Hipertensi & 5 & 5.2 \\
Ada & 91 & 94.8 \\
Tidak ada & 96 & 100.0 \\
$\quad$ Total &
\end{tabular}

Tabel 4 menunjukkan bahwa pengaruh riwayat penyakit (dalam hal ini terjadi kelainan kardiovaskuler) terhadap keikutsertaan responden pada program KB pil yaitu pada PJK, hanya 1 orang $(1,0 \%)$, dan pada penyakit hipertensi, ada 5 orang $(5,2 \%)$ yang mengidap penyakit hipertensi. 
Tabel 5. Faktor Orang Lain yang Mempengaruhi Keikutsertaan PUS Terhadap Program Pil KB

\begin{tabular}{lcc}
\hline & Frekuensi & $\begin{array}{c}\text { Persentasi } \\
(\%)\end{array}$ \\
\hline Pengaruh Suami & & \\
Ada & 26 & 27.1 \\
Tidak ada & 70 & 72.9 \\
Pengaruh Ortu & & \\
Ada & 15 & 15.6 \\
Tidak ada & 81 & 84.4 \\
Pengaruh Mertua & & \\
Ada & 6 & 6.3 \\
Tidak ada & 90 & 93.8 \\
Pengaruh Guru Spiritual & \\
Ada & 5 & 5.2 \\
Tidak ada & 91 & 94.8 \\
Pengaruh Kerabat & & \\
Ada & 22 & 22.9 \\
Tidak ada & 74 & 77.1 \\
Pengaruh Bidan & & \\
Ada & 51 & 53.1 \\
Tidak ada & 45 & 46.9 \\
Pengaruh Dokter & & \\
Ada & 10 & 10.4 \\
Tidak ada & 86 & 89.6 \\
$\quad$ Total & 96 & 100.0 \\
\hline Sumber: Data primer & \\
\hline
\end{tabular}

Sumber: Data primer

Tabel 5 menunjukkan bahwa pengaruh orang lain (suami, orang tua, mertua, guru spiritual, kerabat, bidan, dan dokter) terhadap keikutsertaan responden pada program KB pil terbanyak adalah pengaruh dari bidan, sebanyak 51 orang $(53,1 \%)$. Dan pengaruh dari guru spiritual adalah pengaruh yang paling rendah yaitu sebanyak 5 orang $(5,2 \%)$.

Tabel 6. Faktor Media Massa yang Mempengaruhi Keikutsertaan PUS Terhadap Program Pil KB

\begin{tabular}{lcc}
\hline & Frekuensi & $\begin{array}{c}\text { Persentasi } \\
(\%)\end{array}$ \\
\hline Pengaruh Koran & & 7.3 \\
Ada & 7 & 92.7 \\
Tidak ada & 89 & \\
Pengaruh TV & & 26.0 \\
Ada & 25 & 74.0 \\
Tidak ada & 71 & \\
Pengaruh Radio & & 2.1 \\
Ada & 2 & 97.9 \\
Tidak ada & 94 & \\
\hline
\end{tabular}

Tabel 6 menunjukkan bahwa pengaruh media massa (koran, radio, dan televisi) terhadap keikutsertaan responden pada program KB pil terbanyak adalah pengaruh media TV (26,0\%). Dan pengaruh media radio adalah pengaruh yang paling rendah yaitu sebanyak 2 orang $(2,1 \%)$.

\section{PEMBAHASAN}

Penelitian ini dilakukan di ruang poli KIA Puskesmas Mabelopura Palu. Namun untuk menambah jumlah data, penulis juga melakukan pengambilan data di Pustu dan Posyandu yang masih berada di wilayah kerja Puskesmas Mabelopura. Jumlah sampel yang berhasil didapatkan yaitu 48 sampel case dan 48 sampel control, jumlah ini tentu berbeda dengan jumlah sampel yang telah ditentukan. Hal tersebut disebabkan karena keterbatasan pada penelitian yaitu data peserta KB yang berada di puskesmas masih belum lengkap, karena alamat tempat tinggal yang akan diwawancarai tidak ditemukan oleh penulis merupakan kelemahan penelitian ini.

\section{Menurut Karakteristik Demografi (Faktor Umur dan Agama)}

Berdasarkan hasil uji analisis faktor usia dan agama tidak mempunyai hubungan yang bermakna $(P>0,05)$. Jika berdasarkan uji deskriptif menunjukkan bahwa ada perbedaan kelompok usia yang berpengaruh dalam pengambilan keputusan, namun yang paling penting bahwa data tersebut menunjukkan bahwa ada pengaruh faktor usia dalam pengambilan keputusan seorang wanita untuk ikut serta program KB pil atau tidak. Dari data tersebut dapat dilihat bahwa kelompok usia 26-35 tahun paling banyak yang mempengaruhi seorang wanita untuk ikut serta atau tidak ikut serta terhadap program KB pil, dan agama Islam yang paling banyak. Menurut teori, bahwa usia seorang wanita dapat mempengaruhi kecocokan dan akseptabilitas metode-metode kontrasepsi tertentu. Untuk kontrasepsi pil, semua kelompok usia reproduksi cocok untuk menggunakannya. Berdasarkan survei, wanita yang lebih muda (berusia < 25 tahun) lebih menyukai kontrasepsi oral dan metode barier. Pada wanita yang berumur $>35$ tahun, berdasarkan bukti-bukti terakhir menunjukkan bahwa pil 
kombinasi dapat digunakan dengan aman oleh klien berusia > 35 tahun sampai masa menopause, jika tidak terdapat faktor risiko

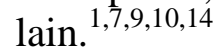

Di beberapa daerah, kepercayaan religius atau budaya dapat mempengaruhi klien dalam memilih metode. Pandangan setiap agama terhadap KB berbeda-beda sesuai ajarannya masing-masing. ${ }^{9,17,24}$

\section{Menurut Sosio-Ekonomi (Faktor Pendapatan \& Tingkat Pendidikan)}

Dari hasil uji analisis faktor pendapatan dan tingkat pendidikan tidak mempunyai hubungan yang bermakna $(\mathrm{P}>0,05)$. Sementara berdasarkan uji deskriptif menunjukkan responden yang memiliki pendapatan rendah lebih banyak dari pada dengan responden yang memiliki pendapatan tinggi. Sementara untuk responden yang memiliki pendapatan menengah tidak mempunyai perbedaan yang terlalu signifikan dengan responden yang memiliki pendapatan rendah. Dan responden yang memiliki tingkat pendidikan menengah lebih banyak. Berdasarkan teori, kemajuan program KB tidak lepas dari tingkat ekonomi masyarakat karena berkaitan erat dengan kemampuan membeli alat kontrasepi yang digunakan. Contohnya, keluarga dengan penghasilan cukup akan lebih mampu mengikuti program KB dari pada keluarga yang tidak mampu, karena bagi keluarga yang tidak mampu KB bukan merupakan kebutuhan pokok. Jika kita membandingkan dengan hasil yang didapatkan, bahwa responden yang memiliki pendapatan rendah lebih banyak berpengaruh untuk ikut serta atau tidak ikut serta program KB pil dikarenakan kemampuan ekonomi mereka yang hanya mampu membeli kontrasepsi murah. ${ }^{7}$

Bila kita melihat hasil yang didapatkan, bahwa kelompok yang tingkat pendidikannya menengah mempunyai pengaruh yang lebih besar dari kelompok lainnya. Hal ini dikarenakan masih banyak populasi masyarakat yang hanya mampu mencapai tingkat pendidikan menengah, namun hal itu tidak membatasi pengetahuan mereka terhadap program KB sehingga dengan tingkat pendidikan yang ada, mereka bisa menentukan kontrasepsi apa yang mereka inginkan.Sesuai dengan teori, tingkat pendidikan tidak saja mempengaruhi kerelaan menggunakan keluarga bencana, tetapi juga dalam pemilihan metode kontrasepsi tertentu. ${ }^{9}$

\section{Menurut Faktor Jumlah Anak}

Berdasarkan hasil uji analisis faktor jumlah anak tidak mempunyai hubungan yang bermakna $(P>0,05)$. Dari hasil uji deskriptif bahwa kelompok responden yang memiliki jumlah anak sedang (memiliki 2 anak) mempunyai pengaruh yang lebih besar terhadap responden untuk ikut atau tidak ikut serta dalam program KB pil. Hal ini dapat dikarenakan oleh upaya responden dalam penjarangan atau pengaturan jumlah anak. Hasil tersebut sesuai dengan UU No.52 Tahun 2009 tentang Perkembangan Kependudukan dan Pembangunan Keluarga dalam Ketentuan Umum Pasal 1 ayat 8 yaitu, Keluarga Berencana adalah upaya mengatur kelahiran anak, jarak dan usia ideal melahirkan, mengatur kehamilan, melalui promosi, perlindungan, dan bantuan sesuai dengan hak reproduksi untuk mewujudkan keluarga yang berkualitas.

Selain itu, menurut teori yang dikemukakan oleh Suratun et all (2008) bahwa dalam pemilihan metode kontrasepsi rasional adalah masa mengatur atau menjarangkan kelahiran. Dalam upaya mengatur atau menjarangankan kelahiran dibutuhkan kriteria kontrasepsi yang diperlukan yaitu: efektivitas tinggi, reversibilitas tinggi karena pasangan masih mengharapkan punya anak lagi, dapat dipakai 3-4 tahun sesuai jarak kelahiran yang direncanakan, serta tidak menghambat produksi air susu ibu (ASI). ${ }^{3}$

\section{Menurut Riwayat Penyakit}

Jika berdasarkan hasil uji analisis faktor riwayat penyakit tidak mempunyai hubungan yang bermakna $(\mathrm{P}>0,05)$ dan hasil uji deskriptif menunjukkan lebih banyak responden yang memiliki riwayat penyakit hipertensi. Menurut teori, bahwa kehamilan menyebabkan perubahan hemodinamik. Selain menjadi kondisi medis yang dapat meningkatkan risiko jika terjadi kehamilan, penyakit jantung koroner juga menjadi kontraindikasi dalam pemakaian kontrasepsi pil, sehingga responden perlu memilih metode kontrasepsi yang lebih efektif. $6,10,15$ 
Hipertensi juga merupakan salah satu tanda kondisi medis bagi ibu untuk tidak boleh hamil. Adanya gangguan sirkulasi pada wanita merupakan kontraindikasi untuk memilih kontrasepsi yang mengandung estrogen. Tekanan darah tinggi $<180 / 110 \mathrm{mmHg}$ merupakan indikasi dari kontrasepsi pil progesteron. Tensi pada orang hamil tidak boleh mencapai 140 systolis atau 90 diastolis. ${ }^{7,9,10,12}$

\section{Menurut Pengaruh Orang Lain}

Berdasarkan hasil uji analisis faktor pengaruh orang lain tidak mempunyai hubungan yang bermakna $(\mathrm{P}>0,05)$. Jika berdasarkan hasil uji deskriptif menunjukkan lebih banyak responden yang mendapat pengaruh dari bidan daripada pengaruh dari lainnya. Menurut Pendit (2006) bahwa anggota keluarga, sanak keluarga, tetangga, dan teman seringkali memiliki pengaruh yang bermakna dalam pemakaian metode kontrasepsi oleh suatu pasangan. Menurut penelitian yang dilakukan oleh Fienalia (2012) dalam Purba (2009) mengatakan bahwa kontrasepsi tidak dapat dipakai oleh istri tanpa kerjasama suami dan saling percaya. Keadaan ideal bahwa pasangan suami istri harus bersama memilih metode kontrasepsi terbaik, saling kerjasama dalam pemakaian, membayar biaya pengeluaran untuk kontrasepsi dan memperhatikan tanda bahaya pemakaian. ${ }^{9,18,19}$

Menurut Laksmi (2009) dalam penelitiannya, peran tokoh agama dalam program KB sangat penting karena peserta $\mathrm{KB}$ memerlukan pegangan, pengayoman, dan dukungan rohani yang kuat yang hanya dapat diberikan oleh tokoh agama. Selain itu, ada juga pengaruh dari petugas kesehatan berupa konseling atau penjelasan kepada peserta $\mathrm{KB}$ untuk memberikan rasa aman kepada peserta $\mathrm{KB}$ dengan menanggulangi efek samping dan komplikasi dari kontrasepsi sedini mungkin, termasuk pelayanan rujukan bila petugas tidak mampu mengatasinya. ${ }^{5,17}$

\section{Menurut Pangaruh Media Massa}

Hasil uji analisis faktor pengaruh orang lain tidak mempunyai hubungan yang bermakna $(\mathrm{P}$ $>$ 0,05). Namun berdasarkan hasil uji deskriptif menunjukkan lebih banyak responden yang mendapat pengaruh dari TV dari pada pengaruh dari radio dan koran. Menurut penelitian yang dilakukan oleh Nasir et all (2010) didapatkan bahwa paparan media massa dan jejaring sosial memainkan peranan penting terhadap wanita dalam memperoleh pengetahuan mengenai tehnik kontrasepsi. Wanita, yang secara teratur menonton TV, mendengarkan radio, atau membaca koran dan majalah akan mendapatkan informasi yang lebih mengenai kontrasepsi, sehingga wanita tersebut memiliki pengetahuan lebih tentang kontrasepsi. Demikian juga wanita yang aktif berpartisipasi dalam organisasi-organisasi, wanita tersebut akan mendapatkan informasi yang lebih mengenai kontrasepsi melalui komunikasi mulut ke mulut. ${ }^{22,23}$

Penelitian tersebut sesuai dengan hasil yang didapatkan oleh Kai-Wen Cheng di Taiwan bahwa media massa dan jejaring sosial berperan penting dalam menyebarkankan pengetahuan mengenai kontrasepsi. Hasil yang didapatkan bahwa wanita yang secara teratur kontak dengan media massa, termasuk menonton TV, mendengarkan radio, membaca majalah, atau membaca surat kabar mempunyai pengetahuan yang lebih mengenai kontrasepsi daripada wanita yang tidak. Selain itu, wanita yang berpartisipasi dalam organisasi memiliki pengetahuan kontrasepsi yang lebih besar daripada rekan-rekan mereka yang tidak berpartisipasi. ${ }^{22,23}$

\section{DAFTAR PUSTAKA}

1. Baziad A. Kontrasepsi hormonal. Edisi 1. Jakarta : PT.Bina Pustaka Sarwono Prawirohardjo ; 2008.

2. BKKBN. Kamus istilah kependudukan dan keluarga berencana nasional (e-book). 2011. Available from URL http://www.bkkbn.go.id/

3. Suratun, Maryani, Hartini et all. Pelayanan keluarga berencana dan pelayanan kontrasepsi. Jakarta : Tim ; 2008.

4. BKKBN. Undang-Undang Republik Indonesia No. 52 Tahun 2009. Diakses dari URL : http://www.bkkbn.go.id/

5. Sulistyawati A. Pelayanan keluarga berencana. Jakarta : Salemba Medika ; 2012.

6. Mochtar R. Sinopsis obstetri. Edisi 2. Jakarta : EGC ; 1998. 
7. Handayani S. Buku ajar pelayanan keluarga berencana. Yogyakarta : Rihama; 2010.

8. Wiknjosastro H. Ilmu kandungan. Edisi 2. Jakarta : PT.Bina Pustaka Sarwono Prawirohardjo ; 2009

9. Pendit B, Wulansari P, Hartono H. Ragam metode kontrasepsi. Jakarta : EGC ; 2007.

10. Saifuddin AB, Affandi B, Enriquito. Panduan praktis pelayanan kontrasepsi. Jakarta : Yayasan Bina Pustaka Sarwono Prawiroharjo ; 2003.

11. Nasution SL. Faktor-Faktor yang mempengaruhi penggunaan MKJP di enam wilayah indonesia (serial on-line). 2011. Available from URL : http://www.bkkbn.go.id/

12. Kusumaningrum F. Faktor-faktor yang mempengaruhi pemilihan jenis kontrasepsi yang digunakan pada pasangan usia subur. 2009. Diakses dari URL: http://eprints.undip.ac.id/

13. USAID. Module family planning for the ethiophian health center team. Hawassa University ; 2003

14. Glasier A, Gebbie A. Keluarga berencana \& kesehatan reproduksi. Edisi 4. Jakarta : EGC ; 2005.

15. Manuaba IB. Kapita selekta penatalaksanaan rutin obstetri ginekologi dan KB. Jakarta : EGC ; 2001.

16. Benson RC, Pernoll ML. Buku saku obstetri \& ginekologi. Jakarta : EGC ; 2002

17. Laksmi IKT. Faktor-faktor yang mempengaruhi pemilihan jenis kontrasepsi yang digunakan pada keluarga miskin. 2009. Diakses dari URL: http://eprints.undip.ac.id/

18. Fienalia RA. Faktor-faktor yang berhubungan dengan MKJP di wilayah kerja Puskesmas Pancoran Mas Kota Depok tahun 2011. 2012. Diakses dari URL: http://lontar.ui.ac.id/

19. Purba JT. Faktor-faktor yang mempengaruhi pemakaian alat kontrasepsi pada istri PUS di Kecamatan Rambah Samo Kabupaten Rokan Hulu tahun 2008. 2009. Diakses dari URL: http://repository.usu.ac.id/

20. Rabe T. Buku saku ilmu kandungan. Jakarta : Hipokrates ; 2002.
21. Taber B. Kapita selekta kedaruratan obstetri dan ginekologi. Jakarta : EGC ; 1994.

22. Nasir JA, Tahir MH, Zaidi AA. Contraceptive Atittude And Behaviour Among University Men: A Study From Punjab Pakistan (serial on-line). 2010. Available from URL : http://www.ncbi.nlm.nih.gov/pubmed/2140 $\underline{9923}$

23. Kai-Wen Cheng. The Effect of Contraceptive Knowledge on Fertility: The Roles of Mass Media and Social Networks (serial on-line). 2011. available from URL http://www.ncbi.nlm.nih.gov/pmc/articles/ PMC3084944

24. Hill, Nicholas J. My Religion Picked My Birth Control: The Influence of Religion on Contraceptive Use. (serial on-line). 2013. Available from URL : http://www.ncbi.nlm.nih.gov 